\title{
Robust Optimization Design of Bolt-Shotcrete Support Structure in Tunnel
}

\author{
Jing-chun WANG, Fa ZHANG, Jia-xiu LIN
}

\begin{abstract}
The uncertainty of rock and soil parameters is one of the key problems to limit the stability of tunnel support structure. Based on this, a robust optimization design method is proposed to reduce the sensitivity of support system to the uncertainty of rock and soil parameters. By defining the design parameters, noise factors and system response, a robust design system for bolt-shotcrete support structure is established. The non-dominant solutions of system robustness and support cost consist of the Pareto Front, then an knee point recognition method is designed to further filter all non-dominant solutions and determine the only optimal solution. The robust optimization design of the bolt-shotcrete support structure is carried out with a tunnel as the engineering background. The results show that the method can not only improve the stability and adaptability of the supporting structure, but also reduce the economic cost to the greatest extent, which provides a reference for the optimization design of other geotechnical engineering supporting structures.
\end{abstract}

Keywords: bolt-shotcrete support; optimization design; robustness; tunnel; uncertainty

\section{INTRODUCTION}

Because of the complex tunnel engineering technology and changeable geological environment, there are a lot of accidents frequently occurring during construction process One of the main forms of tunnel engineering accidents is collapse accident caused by surrounding rock instability [1, 2]. In the process of tunnel excavation, the support structure and surrounding rock are bound together as a unified force system; its stability has a great relation with the safety of the tunnel project construction and operation. Most of the collapse accidents are caused by the problems of the supporting structure, and the engineering accidents caused by structural instability such as shotcrete, steel support and bolt account for about $90 \%$ of the total supporting accidents [3]. Optimizing the supporting parameters to improve the safety and reliability of the supporting structure has become a continuous research topic in the field of tunnel engineering.

Because all kinds of design parameters are in changin $\mathrm{g}$ environment, it is not realistic or even possible to descri be the dynamic characteristics with accurate mathematical models. The uncertainty of environment exists generally, such as modelling error and unknown parameters of engineering structure, which brings much inconvenience to the optimization design of structure. The common structural optimization design (such as reliability design) cannot reflect the variation of design parameters. Because the natural rock and soil have been subjected to long-term geological action, the engineering properties of the soil are different from each other because of the geological origin, geological history and environmental conditions. Therefore, the physical and mechanical parameters of soil have greater spatial variability and randomness, and the limitation of current survey technology and testing level makes it impossible for engineers and technicians to obtain the true values of physical and mechanical parameters of soil. In reliability analysis, the mathematical statistical eigenvalues of random variables are estimated according to the sample data, which is affected by the properties of samples and the size of samples. Therefore, in order to research optimization design of uncertain parameters, finding a way to overcome the unstable influence of uncertain parameters on structural design results is necessary.

The concept of robust design was first proposed by Taguchi in 1970s for quality control systems, and has been rapidly promoted and developed in the fields of mechanical manufacturing, ecosystem, aerospace and so on $[4,5]$. Chen Jianjiang [6] and others put forward a multidisciplinary robust optimization design framework, which combines artificial neural network and robust optimization design to deal with the feature information data of each subsystem to get robust optimal solution. A. Messac and A. Ismail-Yahaya [7] proposed a robust design optimization (RDO) method based on flexible physical programming. RDO method usually seeks to minimize the change of aggregate objective function, so as to achieve robustness optimization. X. Peng and C. Hsein Juang [8] proposed to improve geotechnical engineering robustness design by Monte Carlo method, and study the robustness of the system by studying the change of failure probability in reliability. Padulo et al [9] analysed the advantages and disadvantages of several stochastic methods from the perspective of variable uncertainty propagation, proposed a stochastic method considering efficiency and accuracy and applied it to robust optimization design based on gradient optimization algorithm. Juang [10-12] first introduced robustness into geotechnical engineering, and put forward a robust design method of geotechnical engineering, which considered the influence of geotechnical parameters statistical characteristic uncertainty on the safety. Robustness can be used to evaluate the sensitivity of structural safety performance to the variability of design parameters, and solve the disturbance caused by parameters' uncertainty to structural optimization design.

In this paper, the robust optimization design of the bolt-shotcrete support structure in tunnel is carried out, considering design objectives and design constraints. There are two different criteria for robust design, one is to improve the robustness by reducing the maximum deformation of the vertical displacement, and the other is to improve the economic efficiency by reducing the cost. Any improvement of one goal is at the expense of other goals. In order to meet the security and economic requirements, the non-dominant solutions are calculated of each set of design parameters under the two constraints of 
tunnel arch displacement variation standard deviation and bolt-shotcrete support structure cost. The Pareto front is formed by these non-dominant solutions, which can be called optimal design set.

\section{ROBUST OPTIMIZATION DESIGN OF BOLT- SHOTCRETE SUPPORT STRUCTURE IN TUNNEL}

The core of robust optimization design is an optimization problem, and the aim of robust optimization is to reduce the target variation caused by the fluctuation of variables and parameters. Because of not considering the influence of uncertainty, the solution of the traditional optimization design may be very sensitive to these uncertainties. Compared with the traditional deterministic optimization problems, one of the notable features of robust optimization is the need for continuous uncertainty analysis in the process of optimization, to reduce the dependence of design targets on uncertain factors, make the design results insensitive to uncertain factors. The process of robust optimization design of tunnel boltshotcrete support structure is shown in Fig. 1.

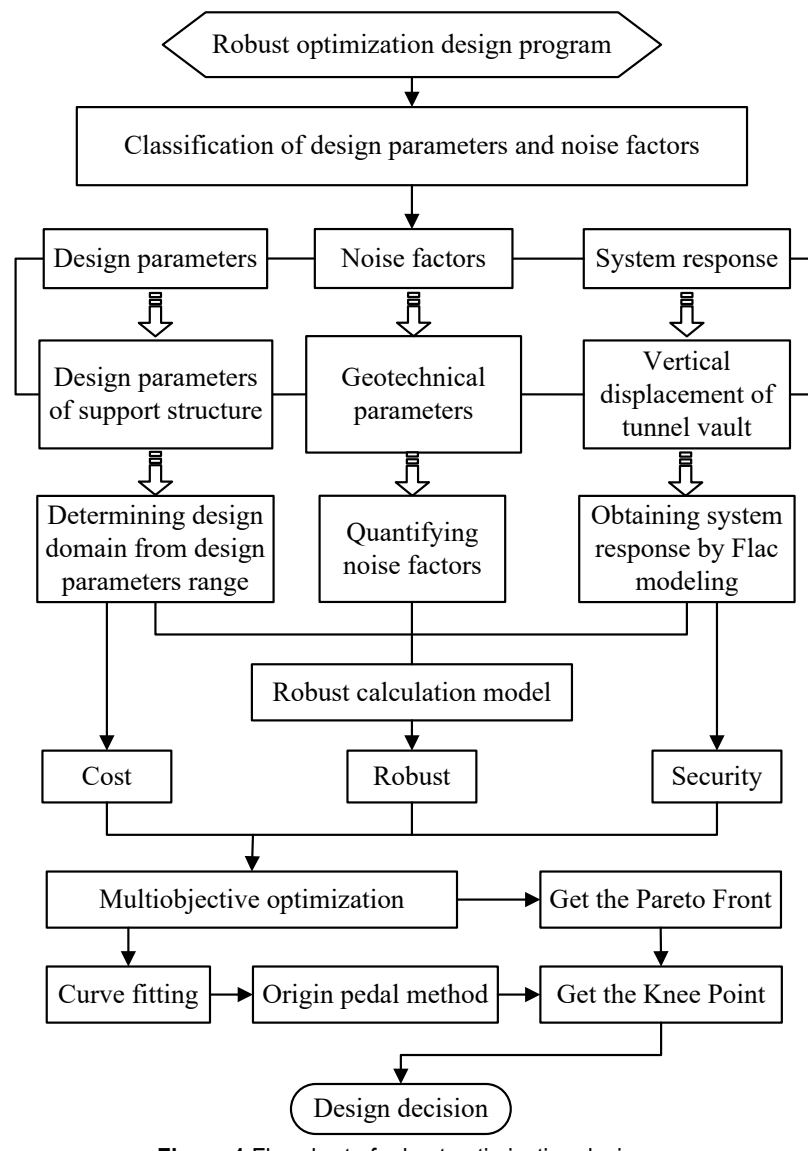

Figure 1 Flowchart of robust optimization design

\subsection{Robustness Index}

It is one of the most difficult problems for the academic and engineering circles to study the robustness of the engineering structure under the uncertainty of the noise factors. The quantitative research on the structure robustness at home and abroad mainly along two ideas of structural attributes and structure performance [13], the corresponding measure also has two types: attribute-based measure and performance-based measure. The settlement of tunnel vault is of great guiding significance for confirming the stability of surrounding rock, judging the supporting effect, guiding the construction process and ensuring the safety of construction. Therefore, the maximum vault settlement after initial support was selected as the system response in this paper.

The numerical simulation method is used to simulate the bolt-shotcrete support structure of tunnel, and the maximum vertical displacement of the tunnel vault is calculated [14, 15]. FLAC is the abbreviation of Fast Lagrangian Analysis of Continua, originated from fluid dynamics, and first applied in the field of solid mechanics by Willkins. The FLAC3D program has become one of the most important numerical methods in geotechnical engineering mechanics calculation after the withdrawal of ITASCA consulting company in the United States. It is the extension of FLAC two-dimensional computing program in three-dimensional space, used to simulate the mechanical properties of body three-dimensional soil, rock or other materials, especially the plastic rheological properties when reaching the yield limit. Therefore, it is widely used in slope stability analysis, support design and evaluation, underground cavern, tunnel engineering, mine engineering and many other fields.

The FLAC3D model is used to calculate the vault vertical displacement under the combination of different parameters of a possibility design, and then the MATLAB software is applied to solve the standard deviation $\sigma$ of system response (the maximum settlement of vault), which is used as robustness index. $\Sigma$ is smaller, the support system is less sensitive to the uncertainty of geotechnical parameters, and the robustness of the system is better. Conversely, the larger the $\sigma$ is, the more sensitive the system is to the uncertainty of geotechnical parameters, that is, the worse the system's robustness is.

\subsection{Design Parameters}

The tunnel support system of composite lining is the most commonly used method in China, mainly divided into two kinds of lining, outer layer flexible support (initial support) and surrounding rock stabilization (secondary lining). The initial support plays a major supporting role in the whole supporting system, which can ensure the stability and safety of the tunnel during construction. Bolt and shotcrete are mainly used to support the surrounding rock, so we called it bolt-shotcrete support in the following. When the surrounding rock is in bad geological section and a weak fractured zone, the mesh reinforcement and steel arch are added to improve the strength and stiffness of the support. By rapidly controlling or restricting the movement and deformation of surrounding rock, the bolt-shotcrete support structure can improve the strength of surrounding rock, adjust and improve the stress state of surrounding rock, and maximize the self-bearing ability of surrounding rock, so as to achieve long-term stability of surrounding rock of tunnel. It can be said the bolt-shotcrete support is the most common and basic supporting form and supporting method in modern tunnel engineering.

In the tunnel bolt-shotcrete support system, the design parameters are mainly affected by bolt, shotcrete, mesh reinforcement and steel arch. When the design of mesh reinforcement and steel arch is fixed, several factors such 
as bolt length, bolt ring spacing, shotcrete model and shotcrete thickness are mainly considered. By determining the range and step of each design parameter, the design domain of tunnel bolt-shotcrete support structure can be obtained. Then, all the possibilities in the design domain are screened by optimization design until the only optimal solution is determined.

\subsection{Noise Factors}

The goal of robust design is to reduce the sensitivity of the system to the uncertain factors and to improve the stability and fault tolerance of the system. Due to the large spatial variability and randomness of geotechnical parameters, coupled with the limitation of current reconnaissance technology and testing level, engineers and technicians cannot get the true value of rock and soil's physical-mechanical parameters. It can be said that the uncertainty of rock and soil parameters has become one of the difficult problems to restrict the development of tunnel engineering. In this paper, the factors which are difficult to control and accurately measure in geotechnical engineering are called noise factors, such as surrounding rock density, internal friction angle and cohesive force, etc [16]. In practical engineering, it is often easy to know the average value of the noise factor and the corresponding coefficient of variation according to the previous experience. The fluctuation range of the noise factor $\left[x_{\min }\right.$, $\left.x_{\max }\right]$ can be calculated by the following formula.

$$
\left\{\begin{array}{c}
x_{\min }+\mu+x_{\max }=3 \mu \\
\sqrt{\frac{\left(x_{\min }-\mu\right)^{2}+\left(x_{\max }-\mu\right)^{2}}{n-1}}=\sigma \\
\frac{\sigma}{\mu}=C V_{\max }
\end{array}\right.
$$

where $x_{\min }$ is the minimum value of the noise factor; $x_{\max }$ is the maximum value of the noise factor; $\mu$ is the mean of noise factors; $n$ is the sample number; $C V_{\max }$ is the maximum value of variation coefficient.

\subsection{Cost}

Any geotechnical engineering system design should consider the cost. Because the design of mesh reinforcement and steel arch is fixed, this cost cannot be counted in cost calculation. So the tunnel bolt-shotcrete support total cost includes the cost of concrete and bolt, whose calculation formula is as follows:

$$
C=C_{1}+C_{2}
$$

where $C$ is the total cost of bolting and shotcrete supporting structure; $C_{1}$ is the cost of shotcrete; $C_{2}$ is the cost of bolt.

$$
C_{1}=c \cdot \delta \cdot C_{1}^{0}
$$

where $c$ is the circumference of support structure section; $\delta$ is the thickness of shotcrete; $C_{1}^{0}$ is the unit price of concrete per cubic meter.

$$
C_{2}=\omega \cdot L \cdot n \cdot \frac{1}{N}
$$

where $\omega$ is the unit price of per mete bolt; $L$ is bolt length; $n$ is the number of the bolt; $N$ is bolt ring spacing.

\subsection{Multiobjective Optimization}

Applying MATLAB software to optimize the system response (the standard deviation of vault vertical displacement) and cost, all non dominated solutions constitute Pareto Front. In many cases, there is a best advantage called knee point on the Pareto frontier produced by double objective optimization. In addition to any design outside the inflection point, it is necessary to make a great sacrifice for another goal in order to improve one's goal a little. Any design in addition to the knee point is necessary to make a great sacrifice in one goal in order to improve another goal a little. Therefore, the design determined by the knee point can be called the only optimal solution in the design domain. At present, the most common method to identify knee point is the normal boundary intersection method at home and abroad, as shown in Fig. 2 [17]. First, connect the beginning and the end point on Pareto Front $f(x)$ to form a straight line $l(x)$, then look for a point $\mathrm{A}\left(m_{0}, n_{0}\right)$ on the curve $f(x)$, so that the distance from the point $\mathrm{A}\left(m_{0}\right.$, $\left.n_{0}\right)$ to the straight line $l(x)$ is the largest. That is the knee point $\mathrm{A}\left(m_{0}, n_{0}\right)$ of the curve $f(x)$ and the unique optimal solution in the design domain.

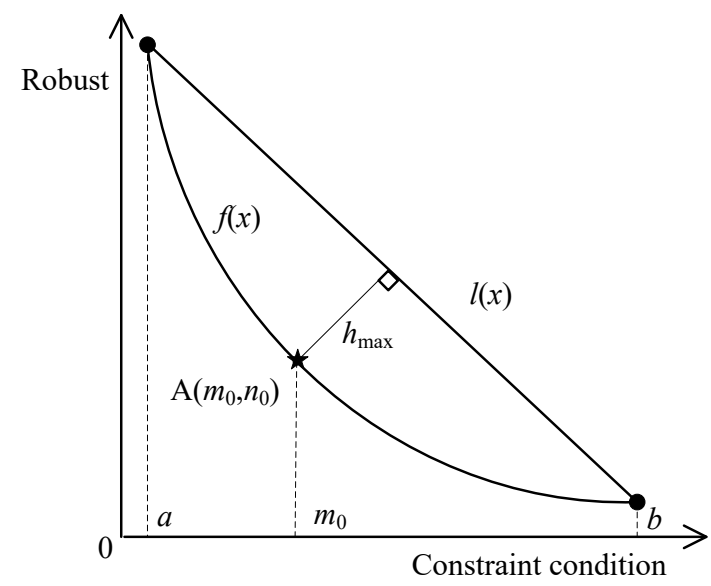

Figure 2 Design domain of $[a, b]$

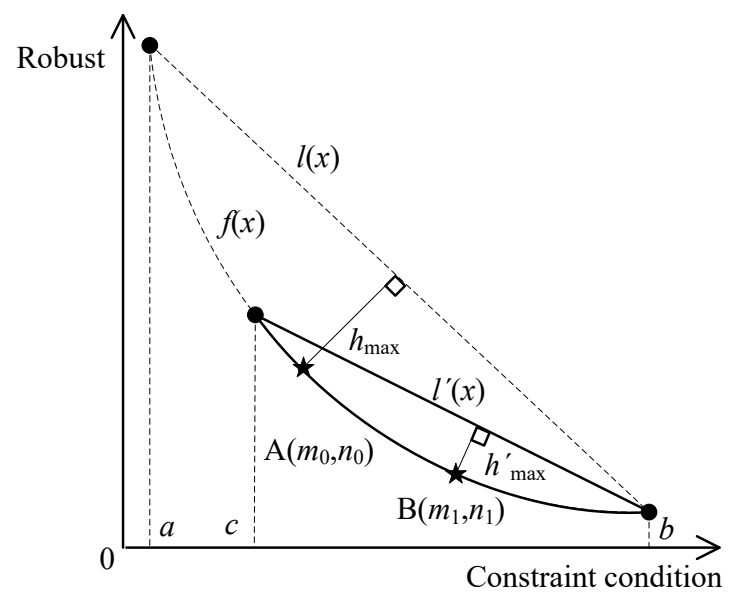

Figure 3 Design domain of $[c, b]$ 
However, there is a problem in the above calculation method. The knee point is very easy to be influenced by the design domain, which leads to the change of the knee point with the change of design domain. For example, we reduce the design domain shown in Fig. 2 from $[a, b]$ to $[c, b]$, where $c$ is a value between $a$ and $m_{0}$. According to normal boundary intersection method, $\mathrm{B}\left(m_{1}, n_{1}\right)$ is identified as the knee point, as shown in Fig. 3. Compared with Fig. 2 and Fig. 3, we can see that the Pareto Front shown in Fig. 3 is a part of the Pareto Front shown in Fig. 2. The knee point $\mathrm{A}\left(m_{0}, n_{0}\right)$ of the design domain $[a, b]$ does not coincide with the knee point $\mathrm{B}\left(m_{1}, n_{1}\right)$ of the design domain $[c, b]$, which is contrary to the definition of the knee point mentioned above. The knee point should be the nature of the Pareto front curve itself, more determined by the shape, nature and relative position of the curve, rather than the upper and lower boundaries of the Pareto Front. Therefore, this article holds that it is not appropriate to identify the knee point by the normal boundary intersection method.

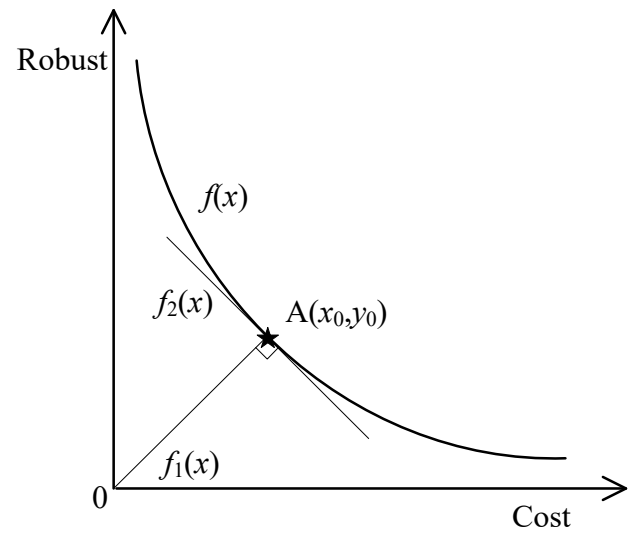

Figure 4 Schematic diagram of knee point

In order to solve the problem that the existing methods are too dependent on the design domain, an origin pedal method was put forward to identify the knee point on Pareto Front curve, which is the only optimal solution in design domain. This method takes account of the functional characteristics of Pareto Front and the coordinate location relationship with axis, applying the concept of derivative to reflect the trend characteristics of Pareto Front fitting curve. The origin pedal method can be described as follows, connecting the origin $(0,0)$ to an arbitrary point $\mathrm{A}\left(x_{0}, y_{0}\right)$ on the line $f(x)$, forming a straight line $f_{1}(x)$. The tangent $f_{2}(x)$ of curve $f(x)$ is over point A. If $f_{1}(x)$ and $f_{2}(x)$ are perpendicular to each other, then the point $\mathrm{A}\left(x_{0}, y_{0}\right)$ is the knee point, as shown in Fig. 4. The specific calculation process of $\mathrm{A}\left(x_{0}, y_{0}\right)$ is as follows:

$\left\{\begin{array}{c}x_{0} \Leftarrow f^{\prime}\left(x_{0}\right)=-\frac{x_{0}}{f\left(x_{0}\right)} \\ y_{0}=f\left(x_{0}\right)\end{array}\right.$

where $f^{\prime}\left(x_{0}\right)$ is the guide value of Pareto Front function $f(x)$ at the point $\mathrm{A}\left(x_{0}, y_{0}\right)$.

\section{APPLICATION EXAMPLE 3.1 Engineering Survey}

A railway tunnel has a full length of $3579 \mathrm{~m}$, and the crossing section is subordinate to the hilly and gully area of Ordos. The tunnel outcropping area is mainly composed of Triassic sandstone and mudstone. The occurrence of strata is gentle undulating and bedding development, which provides a necessary condition for the occurrence of groundwater. The tunnel is a horseshoe tunnel, whose inner contour is designed according to the target value of the train running speed of $120 \mathrm{~km} / \mathrm{h}$. According to the design requirements of the shotcrete construction method, the composite lining with a curved wall and a pitching arch is adopted, the shotcrete and steel frame are used in the initial support, and the bench cut method is selected in construction.

In this paper, K84+694 section is selected to study the robust optimization design of bolt-shotcrete support. This section mainly weathered sandstone strata, whose rock grade is $\mathrm{V}$. The $\varnothing 22$ mortar anchor was arranged as plum blossom type in arch wall, with one I16 steel frame set per meter. The arch wall is laid with $\varnothing 8$ steel mesh, whose grid spacing is $20 \times 20 \mathrm{~cm}$. The lining structure of the section is as shown in Fig. 5, and the schematic diagram of steel mesh is shown in Fig. 6.

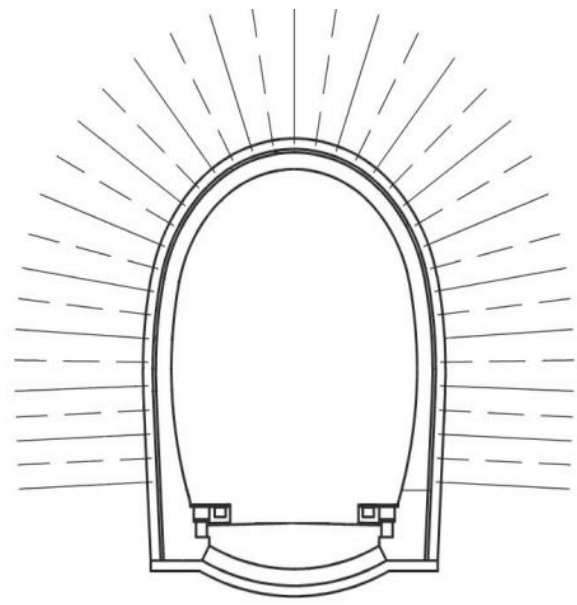

Figure 5 Tunnel section map

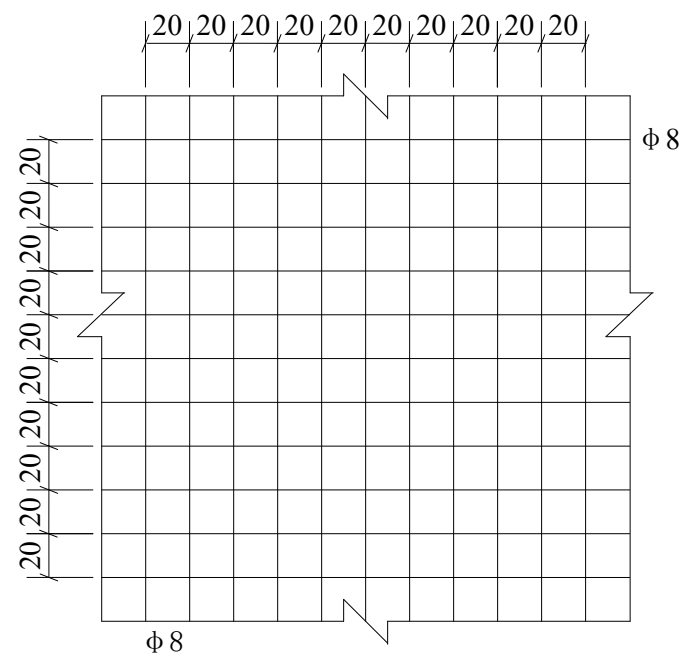

Figure 6 Schematic diagram of steel mesh 


\subsection{Design Parameters}

We have fully read the relevant design specifications, such as "code for design of railway tunnels" (TB100032005), "technical specification for spray tunnel construction of railway tunnels" (TB10108-2002) and "code for construction of railway tunnels" (TB102042002). The range and step length of the shotcrete model, the shotcret thickness, the bolt length and the bolt ring spacing are preliminarily determined, as shown in Tab. 1.

Table 1 Bolt-shotcrete support parameters

\begin{tabular}{|c|c|c|c|}
\hline $\begin{array}{c}\text { Concrete } \\
\text { type }\end{array}$ & $\begin{array}{c}\text { Concrete } \\
\text { thickness }(\mathrm{m})\end{array}$ & $\begin{array}{c}\text { Bolt length } \\
(\mathrm{m})\end{array}$ & $\begin{array}{c}\text { Bolt ring } \\
\text { spacing }(\mathrm{m})\end{array}$ \\
\hline C20 & 0.10 & 2.5 & 0.8 \\
\hline C25 & 0.14 & 3.0 & 1.0 \\
\hline C30 & 0.18 & 3.5 & 1.2 \\
\hline- & 0.22 & 4.0 & 1.4 \\
\hline- & 0.26 & - & - \\
\hline- & 0.30 & - & - \\
\hline
\end{tabular}

As known from Tab 1, there are three design parameters of spray shotcrete type, six design parameters of spray shotcrete thickness, four design parameters of bolt length and bolt ring spacing, then we can obtained 288 possibilities for a theoretical design. However, Hook, Brown, the American Association of Engineers and the United States Bureau of Mines have proposed that the minimum length of the bolt rod should be at least twice the distance between the anchors' circumferential spacing. Therefore, the combination of parameters which do not meet this requirement is excluded from the above design parameters, that is, the design combination of $2.5 \mathrm{~m}$ bolt length and $1.4 \mathrm{~m}$ bolt ring spacing is not considered, then we can obtain 270 designing combination. That is to say, there are 270 possible designs forming the design domain of the bolt-shotcrete support structure in this tunnel.

\subsection{Noise Factors}

According to the formula (1), the value of surrounding rock mass, internal friction angle and cohesive force is calculated respectively, as shown in Tab. 2.

Table 2 Physical and mechanical parameters of surrounding rock

\begin{tabular}{|c|c|c|c|}
\hline Project parameter & Bulk density $\gamma\left(\mathrm{kN} / \mathrm{m}^{3}\right)$ & Internal friction angle $\phi\left(^{\circ}\right)$ & Cohesion $C(\mathrm{MPa})$ \\
\hline Mean value & 20 & 25 & 0.1 \\
\hline Coefficient of variation & $0.01 \sim 0.08$ & $0.05 \sim 0.4$ & $0.2 \sim 0.5$ \\
\hline Span & {$[18.4,21.6]$} & {$[15,35]$} & {$[0.05,0.15]$} \\
\hline
\end{tabular}

Table 3 Physical and mechanical parameters of the bolt

\begin{tabular}{|c|c|c|c|c|}
\hline Material & Sectional area $\left(\mathrm{mm}^{2}\right)$ & Modulus of elasticity $(\mathrm{GPa})$ & Bulk modulus $(\mathrm{GPa})$ & Poisson ratio $v$ \\
\hline Bolt & 380 & 200 & 167 & 0.3 \\
\hline
\end{tabular}

Table 4 Physical and mechanical parameters of shotcrete

\begin{tabular}{|c|c|c|c|}
\hline Concrete type & Elastic modulus $(\mathrm{MPa})$ & Poisson ratio & 0.2 \\
\hline C20 & $2.55 \times 10^{4}$ & 0.2 & $2.3 \times 10^{3}$ \\
\hline C25 & $2.80 \times 10^{4}$ & 0.2 & $2.4 \times 10^{3}$ \\
\hline C30 & $3.00 \times 10^{4}$ & $2.5 \times 10^{3}$ & \\
\hline
\end{tabular}

\subsection{FLAC3D Model Analysis}

(1) Basic assumption

In order to facilitate the establishment of the model, it is necessary to make the following basic assumptions about the tunnel according to the actual situation in the simulation process:

All the problems involved in the bolt-shotcrete supporting structure of the surrounding rock of the tunnel are considered as the problem of plane strain;

Disregarding the effects of groundwater;

Without considering the steel arch, the relevant parameters of the shotcrete are increased, replacing the support effect of the steel arch on the surrounding rock;

The anchor, concrete and surrounding rock and soil are considered as ideal elastic bodies, which are fully subordinate to the Mole - Coulomb strength yield criterion.

(2) Simulation parameters

In the process of FLAC3D simulation, various simulation parameters are involved, including geotechnical engineering parameters, bolt element parameters, spray concrete parameters, etc. In this paper, the solid elastoplastic element is used in the surrounding rock structure, the CABLE structural element is used in the bolt, and solid elastoplastic element is used for shotcrete.
The contact surface between bolt and surrounding rock has friction and adhesion. Under this constraint mode, the bolt has only one degree of freedom of axial displacement, and there is friction between bolt and surrounding rock caused by adhesion and slip. Therefore, the structural unit CABLE is used in the FLAC3D simulation to analyse the anchor rod. The stress of the inter facial layer between the surrounding rock and the anchor rod will prevent the deformation of the surrounding rock after the anchor rod is applied, and the interaction between bolts and the surrounding rock will result in the deformation of the bolts. The physical and mechanical parameters of the bolts are shown in Tab. 3.

According to the mechanical properties of concrete materials, the constitutive models of concrete are divided into linear and nonlinear elastic models, as well as non elastic models, such as plastic theory, other mechanics theory and so on. Tunnel excavation leads to deformation of surrounding rock, then the initial support is subjected to great stress and deformation. The shotcrete structure will inevitably enter to plastic deformation from elastic deformation. In this paper, the shotcrete is used as a solid element and is considered as an elastoplastic material, and its material parameters are shown in Tab. 4. 


\section{3) Model range}

The simulations carried out on the premise of the ideal elastic body model and the Moore Coulomb yield criterion. The range of calculation model is $40 \mathrm{~m}$ in the horizontal direction, $76 \mathrm{~m}$ in the vertical direction, $36 \mathrm{~m}$ in the buried depth and 4 times total height of the tunnel at the upper and lower boundary, and the left and right boundary is 7 times the total span of the tunnel, and $1 \mathrm{~m}$ of the depth. The meshes of the model surrounding rock, initial support grid and bolt mesh are shown in Fig. 7.

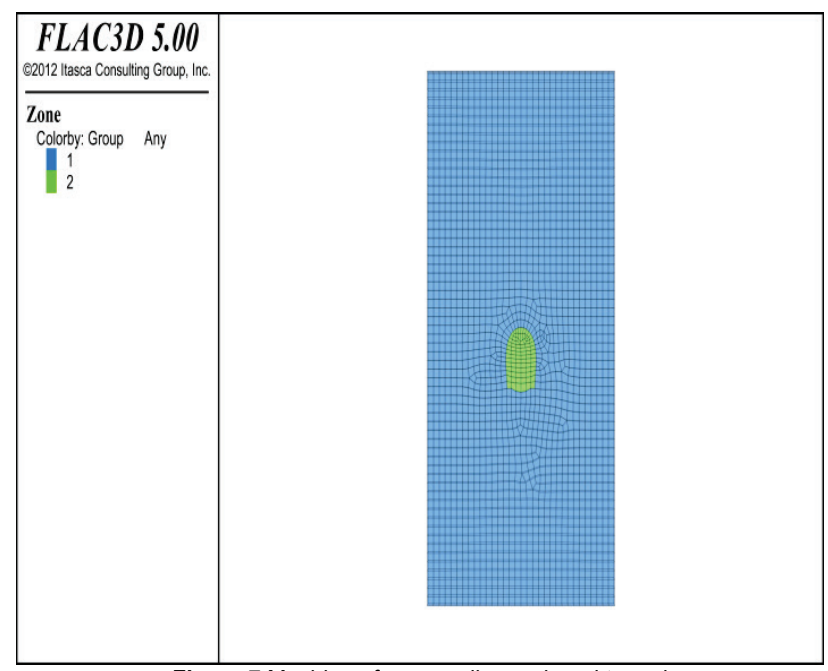

Figure 7 Meshing of surrounding rock and tunnel

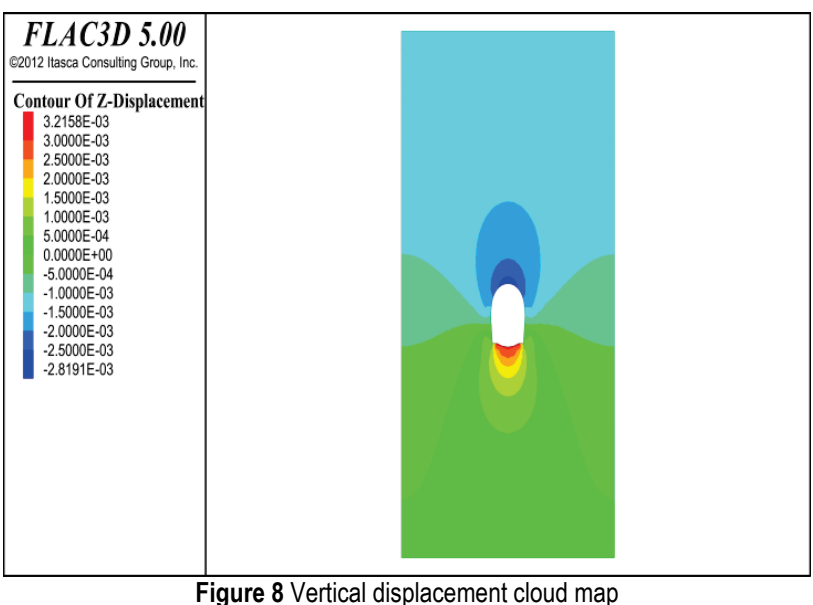

Boundary conditions and loads

The lateral boundary and the bottom surface of the model are displacement boundaries. The displacement boundary conditions on both sides of the model only restrict horizontal movement. The bottom displacement boundary of the model only constrains its vertical movement, the surface as the upper boundary of the model is the free boundary. This design only considers the gravity load of the rock and soil itself, the vertical stress takes the stress of the upper rock and the horizontal stress is 0.55 times vertical stress.

Simulation results

The FLAC3D simulation is carried out with the example of bolt-shotcrete support for "anchor length $2.5 \mathrm{~m}$ + Bolt ring spacing $0.8 \mathrm{~m}+$ concrete model $\mathrm{C} 20+$ concrete thickness $0.10 \mathrm{~m}$ ". The vertical displacement cloud is shown in Fig. 8.

\subsection{Optimization Design}

After FLAC3D numerical simulation, MATLAB standard deviation calculation and cost calculation, cost and robustness indexes (Vault vertical displacement standard deviation $\sigma$ ) of 270 possible designs were obtained respectively. The MATLAB software is applied to optimize system response (the standard deviation of the vault vertical displacement) and cost of the 270 design schemes. 30 groups of non-innervation solutions are obtained and form the Pareto Front, as shown in Fig. 9.

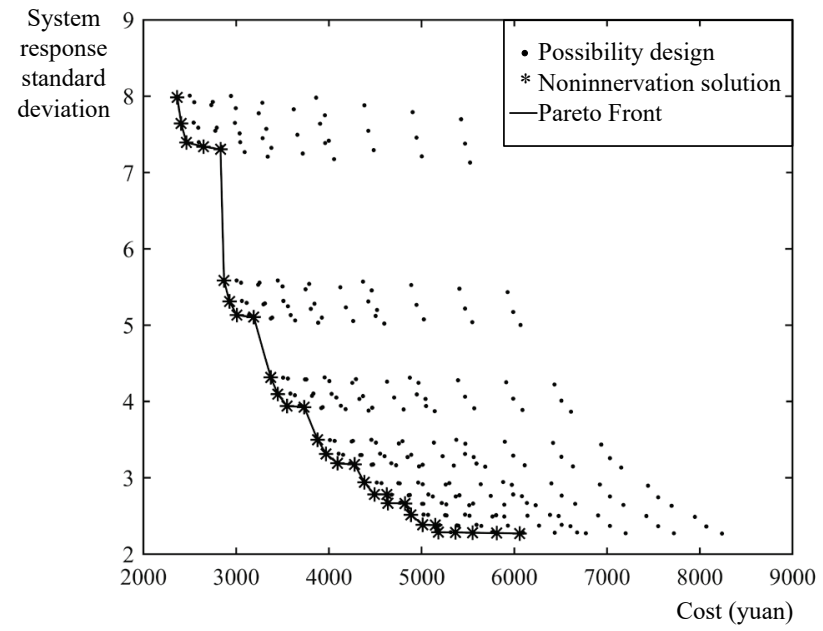

Figure 9 Pareto Front

In order to make further analysis of the 270 possibility designs, we use thousand yuan as the cost unit and (e-4) as robust index unit, then the cost and robustness index is unified to the same order of magnitude. As shown in Fig. 9, the Pareto Front is made up of a series of discrete points. In order to further study the properties of Pareto Front, we use exponential function to fit it and get a smooth curve, as shown in Fig. 10. The Pareto curve fitting function is shown in the following form.

$$
f(x)=38.27 e^{-0.6892 x}+0.2774 e^{0.2977 x}
$$

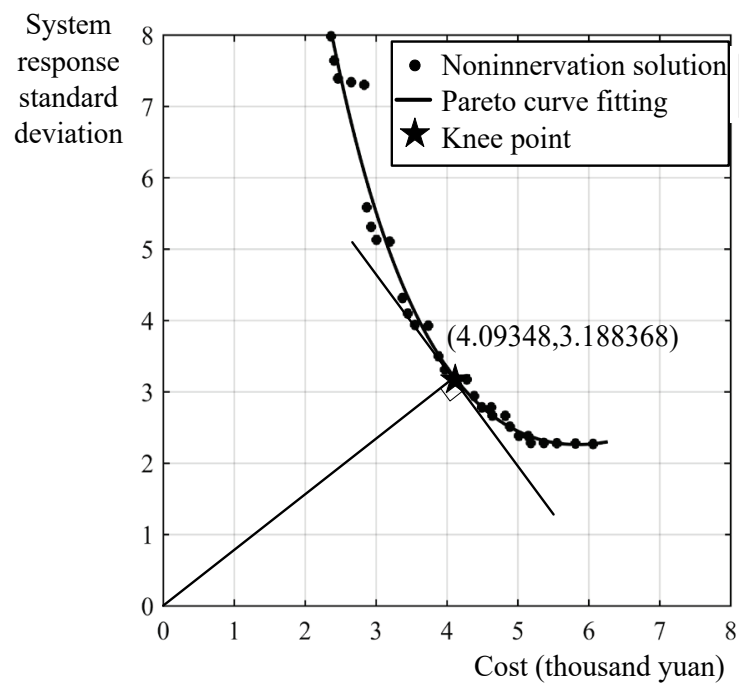

Figure 10 Pareto curve fitting

According to the Eq. (5), the optimal design point on the Pareto frontier is $(4.09348,3.188368)$, with the scheme 
parameters is shown in Tab. 5. That is to say, using concrete of $\mathrm{C} 30$, concrete thickness of $0.220 \mathrm{~m}$, bolt length of $3 \mathrm{~m}$, and bolt ring spacing of $1.4 \mathrm{~m}$ can make the tunnel support system achieve the dual optimum of robustness and economic cost.

Table 5 Optimal design scheme

\begin{tabular}{|c|c|c|c|}
\hline $\begin{array}{c}\text { Concrete } \\
\text { model }\end{array}$ & $\begin{array}{c}\text { Concrete } \\
\text { thickness }(\mathrm{m})\end{array}$ & $\begin{array}{c}\text { Anchor length } \\
(\mathrm{m})\end{array}$ & $\begin{array}{c}\text { Bolt ring } \\
\text { spacing }(\mathrm{m})\end{array}$ \\
\hline C30 & 0.22 & 3.0 & 1.4 \\
\hline
\end{tabular}

\subsection{Relative Optimal Solution}

Due to the influence and limitation of construction conditions and other factors, a specific parameter has to be determined under certain working conditions, which requires that the parameter must be processed in a quantitative way in the optimization design process. On this basis, the concept of relative optimal solution is put forward. It is known that a certain design parameter is known, and there will be different Pareto Fronts with the change of other design parameters. Then we can find a knee point on the front of Pareto as the relative optimal solution. The meaning and application of the relative optimal solution are further explained by controlling the relative parameters of the bolt.

The constraints of the bolt length and the bolt ring spacing are invariable. Suppose that the length of anchor rod is $3.5 \mathrm{~m}$ and the circumferential distance is $1 \mathrm{~m}$. Under the constraint of two design parameters, the Pareto front of support structure for shotcrete type and thickness is established, and the robust optimal solution is studied at this time. The Pareto Front curve is shown in Fig. 11.

The function fitting is carried out to the Pareto Front, and the corresponding exponential function is obtained as follows.

$$
y=1523 e^{-1.727 x}+13.21 e^{-0.2753 x}
$$

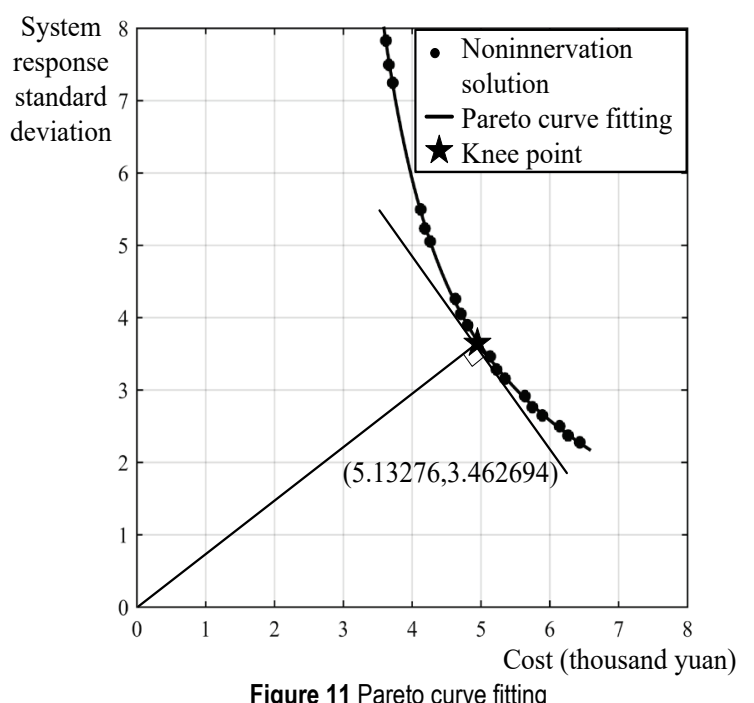

According to the Eq. (5), we calculate the knee point on the Pareto Front under the constraint of above design parameters, then the knee point $(5.13276,3.462694)$ is the relative optimal solution at this time. The corresponding support scheme parameters are shown in Tab. 6. That is to say, when the bolt length is determined to be $3 \mathrm{~m}$ and the bolt ring spacing is determined to be $1.4 \mathrm{~m}$, the support scheme of concrete type C30 and concrete thickness of $0.22 \mathrm{~m}$ can make the tunnel support system achieve the double best of robustness and economic cost under this constraint condition.

Table 6 Relative optimal solution scheme (bolt length and ring spacing is fixed)

\begin{tabular}{|c|c|c|c|}
\hline $\begin{array}{c}\text { Concrete } \\
\text { model }\end{array}$ & $\begin{array}{c}\text { Concrete } \\
\text { thickness }(\mathrm{m})\end{array}$ & $\begin{array}{c}\text { Anchor length } \\
(\mathrm{m})\end{array}$ & $\begin{array}{c}\text { Bolt ring } \\
\text { spacing }(\mathrm{m})\end{array}$ \\
\hline 3.5 & 1.0 & C20 & 0.22 \\
\hline
\end{tabular}

Through the above application and analysis, the best support scheme is obtained when the design parameters are limited. It verifies the feasibility of the relative optimal solution in local optimum design, and proves the universality and reliability of the robust optimization design in the application of structural optimization, and provides a new idea and theoretical basis for the optimization design of tunnel and underground engineering.

\section{CONCLUSION}

In this paper, the authors analysed the superiority of robust optimization design, introduced the concept of robustness into the optimal design of tunnel supporting structure, and proposed a robust design method of boltshotcrete supporting structure. This method solved the variability problem of geotechnical engineering parameters which cannot be solved by reliability design and other common methods, and improved the stability of optimization design results.

Taking a tunnel as the engineering background, the FLAC3D software is used for numerical simulation of tunnel excavation and bolt-shotcrete support, and the standard deviation of vault displacement under the influence of geotechnical engineering parameters is calculated. Taking the standard deviation and the corresponding support cost as the constraint objective, the Pareto Front of the bolt-shotcrete support scheme is established by non dominated solution calculating, which lays the foundation for further search of optimal solution.

An origin pedal method was proposed, which can be simply described as that the connection between the knee point on the Pareto Front fitting curve and the origin is perpendicular to the tangent of the curve on the point. This method took account of the function characteristics of Pareto Front and the relative position of the coordinate axis, and solved the problem that the existing methods are too dependent on the design domain. Finally, the unique optimal solution was defined as the design decision through the concept of the knee point.

\section{Acknowledgements}

The present work was supported by National Natural Science Foundation of China (Grant No. 51608336). The financial supports are gratefully acknowledged.

\section{REFERENCES}

[1] Zhang, J., Chen, Y., Sun, Y., et al. (2017). Analysis on Distribution Characteristics of Tunnel Collapse Accident in China from 2006 to 2016. Journal of Catastrophology, 32(4), 
132-137.

[2] Xiong, S. (2012). Basic research of break angle in shallowburied tunnel. Beijing Jiaotong University.

[3] Yang, J. (2011). The effect on tunnel support structure and ground settlement by stress release and excavation method. Xiangtan University.

[4] Brik, B. A., Ghanmi, S., Bouhaddi, N., et al. (2008). Robust design in structural mechanics. International Journal for Computational Methods in Engineering Science and Mechanics, 8(1), 39. https://doi.org/10.1080/15502280601006264

[5] Beyer, H. G. \& Sendhoff, B. (2007). Robust optimizationa comprehensive survey. Computer Methods in Applied Mechanics and Engineering, 196(33), 3190. https://doi.org/10.1016/j.cma.2007.03.003

[6] Chen, J., Xiao, R., \& Zhong, Y. (2005). A response surface based hierarchical approach to multidisciplinary robust optimization design. Int $J$ Adv Manuf Technol, 26, 301-309. https://doi.org/10.1007/s00170-004-2080-0

[7] Messac, A. \& Ismail-Yahaya, A. (2002). Multiobjective robust design using physical programming. Struct Multidisc Optim, 23, 357-371. https://doi.org/10.1007/s00158-002-0196-0

[8] Peng, X., Li, D. Q., Cao, Z. J. et al. (2017). Reliabilitybased robust geotechnical design using Monte Carlo simulation. Bull Eng Geol Environ, 76(3), 1217-1227. https://doi.org/10.1007/s10064-016-0905-3

[9] Padulo, M., Campobasso, M. S., \& Guenov, M. D. (2011) Novel uncertainty propagation method for robust aerodynamic design. AIAA Journal, 49(3), 530-543. https://doi.org/10.2514/1.J050448

[10] Xu, C., Wang, L., Tien, Y. M. et al. (2014). Robust design of rock slopes with multiple failure modes: modeling uncertainty of estimated parameter statistics with fuzzy number. Environ Earth Sci, 72, 2957-2969. https://doi.org/10.1007/s12665-014-3201-1

[11] Juang, C., Wang, L., Liu, Z., et al. (2013). Robust geotechnical design of drilled shafts in sand: new design perspective. Journal of Geotechnical and Geoenvironmental Engineering, 139(12), 2007. https://doi.org/10.1061/(ASCE)GT.1943-5606.0000956

[12] Juang, C. H., Liu, Z., \& Atamturktur, H. S. (2012). Reliability-based robust geotechnical design of retaining walls. Sound Geotechnical Research to Practice. San Diego: ASCE, 514- 524.

[13] Lv, D., Song, P., Cui, S., et al. (2011). Structural robustness and its assessment indicators. Journal of Building Structures, 32(11), 44-54

[14] Dai, Y., Zhu, X., Chen, L. S., Liu, H., et al. (2015). A new multi-body dynamic model of a seafloor miner and its trafficability evaluation. International Journal of Simulation Modelling, 14(4), 732-743. https://doi.org/10.2507/IJSIMM14(4)CO19

[15] Dai, Y., Chen, L. S., Zhu, X., et al. (2016). Modelling and simulation of a mining machine excavating seabed massive sulfide deposits. International Journal of Simulation Modelling, 15(2), 377-387. https://doi.org/10.2507/IJSIMM15(2)C010

[16] Huang, H., Gong, W., Hsein Juang, C., et al. (2014). Robust geotechnical design of gravity retaining wall. Journal of Tongji University (Natural Science), 42(3), 377-385.

[17] Hsein Juang, C., Wang, L., Hsieh, H.-S., et al. (2014). Robust geotechnical design of braced excavations in clays. Structural Safety, 49, 37- 44. https://doi.org/10.1016/j.strusafe.2013.05.003

\section{Contact information:}

Jingchun WANG, Professor

(Corresponding author)

College of Civil Engineering, Shijiazhuang TieDao University (STDU),

17 Northeast, Second Inner Ring, Shijiazhuang, Hebei, China

E-mail: wjc36295@163.com

Fa ZHANG, Master

College of Civil Engineering, Shijiazhuang TieDao University (STDU), 17 Northeast, Second Inner Ring, Shijiazhuang, Hebei, China

E-mail: 1849568695@qq.com

\section{Jiaxiu LIN, Master}

College of Civil Engineering, Shijiazhuang TieDao University (STDU), 17 Northeast, Second Inner Ring, Shijiazhuang, Hebei, China

E-mail: 1947849406@qq.com 